\title{
Comparing the "Modified Split and Fender" and "Shortwall" Methods for the Pillar Recovery in Room and Pillar Coal Mining Using A 3D Finite Difference Modeling in Tabas Central Coal Mine, Iran
}

\author{
M. Yaghobi ${ }^{1}$, R. Rafiee ${ }^{1}$, M. Najafi ${ }^{2 *}$ \\ 1- Dept. of Mining, Petroleum and Geophysics, Shahrood University of Technology, Iran \\ 2- Dept. of Mining and Metallurgy, Yazd University, Iran \\ * Corresponding Author: mehdinajafi@yazd.ac.ir \\ (Received: November 2016, Accepted: July 2017)
}

\begin{tabular}{|c|c|}
\hline Keywords & Abstract \\
\hline Room and Pillar & $\begin{array}{l}\text { Selecting a suitable pillar recovery method is one of the most } \\
\text { important issues in the room and pillar mining. The main purpose }\end{array}$ \\
\hline illar Recovery & of this study is to compare two methods for pillar recovery in \\
\hline oal Mine & Tabas central coal mine (TCM). Among the existing methods, the \\
\hline Modified Split and Fender & $\begin{array}{l}\text { two methods, "Modified split and fender" and "Shortwall" are } \\
\text { chosen for the numerical modeling. The three dimensional finite }\end{array}$ \\
\hline cortwall Min & difference method (FLAC3D software) is used to model these \\
\hline FLAC3D Software & $\begin{array}{l}\text { methods. In the next step, the vertical stress and displacement, the } \\
\text { plastic zone condition and the safety factor during each stage of }\end{array}$ \\
\hline \multicolumn{2}{|c|}{$\begin{array}{l}\text { pillar recovery were compared for each method. The results of this modeling show that the percentages of } \\
\text { coal recovery for two methods of "modified split and fender" and "shortwall" are around } 70 \% \text { and } 82 \% \\
\text { respectively. Comparing the percentage recovery of coal for these two methods, exhibits that the shortwall } \\
\text { method is more suitable than modified split and fender, for this mine. }\end{array}$} \\
\hline
\end{tabular}

\section{INTRODUCTION}

In the modern and large coal mines which are extracted by caving methods, most of the decisions about design and pillar recovery are made before the extraction operation. In these mines the location and size of the pillar and its recovery method is predetermined. In such mines the pillar should be designed such that the full stability of mine roof can be maintained. In other words, in these cases the drifts and roof stability until the end of mining operation in the recovery time is very important. Yet, if in these methods, for different reasons such as poor quality of roof layer, there is no any chance to extraction of pillars and the percent recovery is reduced and using these methods are not economical.

The room and pillar method is one of the oldest and most common extraction methods in the underground mining that is usually used for coal mining. This method is appropriate for extracting the flat layers [1-3]. The retreat mining methods have great variations in coal industry and have been extensively tested. With respect to the performance and equipment used, the recovery methods of pillar are divided into three groups namely traditional, modern and compound [3].

- The traditional methods: outside lift, split and fender, pocket and wing, Wongawilli and open ending.

- Modern methods: Christmas tree, modified split and fender, modified Wongawilli and shortwall.

- Compound methods: compound methods derived from the combination of two methods "Christmas tree" and "Outside lift of the holding columns".

Many studies have been carried out for the recovery of mining pillars, especially coal in countries such as America, Canada, Australia and India. These studies include a variety of pillar recovery procedures, the risks of pillar recovery and guidelines to reduce the human and financial losses [3-4]. In the studies conducted by Kushwaha and Banerjee in 2005, shortwall recovery method was studied in the coal mines of Balrampur in India [5]. Qiyami studied 
"Christmas tree" and "split and fender" method by using the numerical modeling in Tabas central coal mine. In this study assuming the $75 \%$ recovery for both methods, sequence of cuttings is designed and modeled, and eventually the two methods are compared. In this study the Christmas tree method is introduced as the most appropriate method for pillar recovery [6]. Singh et al. in 2011, using numerical modeling discussed induced stress development during depillaring under varying geo-mining conditions [7]. Liu et al. in 2015, by using 2D numerical modeling analyzed stress distribution in backfilled stopes considering interfaces between the backfill and rock walls [14]. Najafi et al. in 2016, studied the suitable distance between two adjacent panels face in shortwall mining of Tabas central coal mine through numerical modeling. Numerical results show that a suitable distance between two adjacent panels working face is 30 meters in Tabas central coal mine [15].

It is clear that in previous studies the suitable pillar recovery method with regard to stability conditions of pillars is not considered. This research aims to select the appropriate method of pillar recovery for room and pillar method using the numerical modeling in Tabas central coal mine. Accordingly, after examining and comparing the method of pillar recovery, two methods of "modified Split and fender" and "Shortwall", which are the most commonly methods with high mechanization and high production capacity, are selected for pillars recovery. By using the FLAC3D software, the stress and displacement variation over the pillar and plastic zone in the constructed models have been studied during each stage of recovery process. Moreover, an appropriate method for pillars recovery and recovery percentages in each method is determined.

\section{CASE STUDY}

Tabas central coal mine (TCM) is located in Tabas coal region approximately $85 \mathrm{~km}$ south of Tabas in South Khorasan province, Iran. The study is performed on the C1 coal seam which extracted room and pillar method using a continuous miner and LHD. The average depth of main panel is $100 \mathrm{~m}$. The C1 seam dip mostly varied from 11 to 26 degrees and seam thickness is about $2 \mathrm{~m}$. Pillars are squares and width is 15 $\mathrm{m}$ (center to center). Because the rock of immediate roof is very weak, the main entry and crosscuts have $4 \mathrm{~m}$ width (CMRR =37). The entries roof after excavation is supported by rockbolt. In the hanging wall and footwall of coal seam, layers of sandstone, siltstone and mudstone can be seen [8-9]. The stratigraphy column in TCM is shown in Fig. 1 [10].

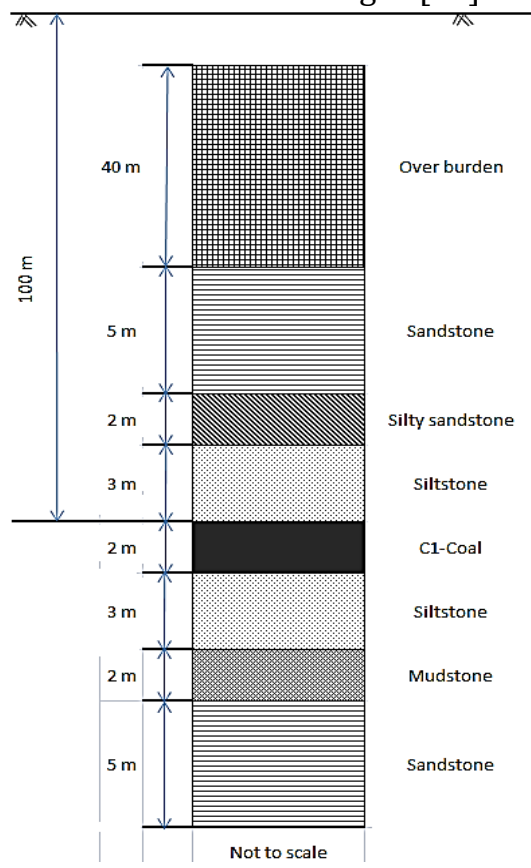

Figure 1. A generalized stratigraphic column at TCM [11]

Initially, the design of the mine was based on the room and pillar method, but currently, this mine is under extraction vie the traditional shortwall method. The main objective of this study is to recover the pillars in the central part of mine. A view of the studied area in TCM is shown in Fig. 2.

\section{NUMERICAL MODELING}

In this research numerical modeling is used for comparison of "modified split and fender" and "Shortwall" method for pillar recovery in room and pillar coal mining in Tabas central coal mine. Based on the gathered information, the geological conditions of Tabas central coal mine can be considered as continuum. Therefore, in this study, the FLAC3D software is used for the simulation of longwall mining process.

Numerical modeling in FLAC3D software for all of five simulation models has been done in 5 steps as follows:

(A) Determination of general layout

(B) Determination of boundaries and material properties

(C) Model preparation (model geometry, meshing and the model behavior) 
(D) Determination of the boundary and initial conditions

(E) Initial running of the program, excavating the model according to the mine geometry, applying the support system and then pillar recovery by two methods of split and fender and shortwall method.

(F) Analysis of the results of numerical modeling and selection of the best method for pillar recovery.

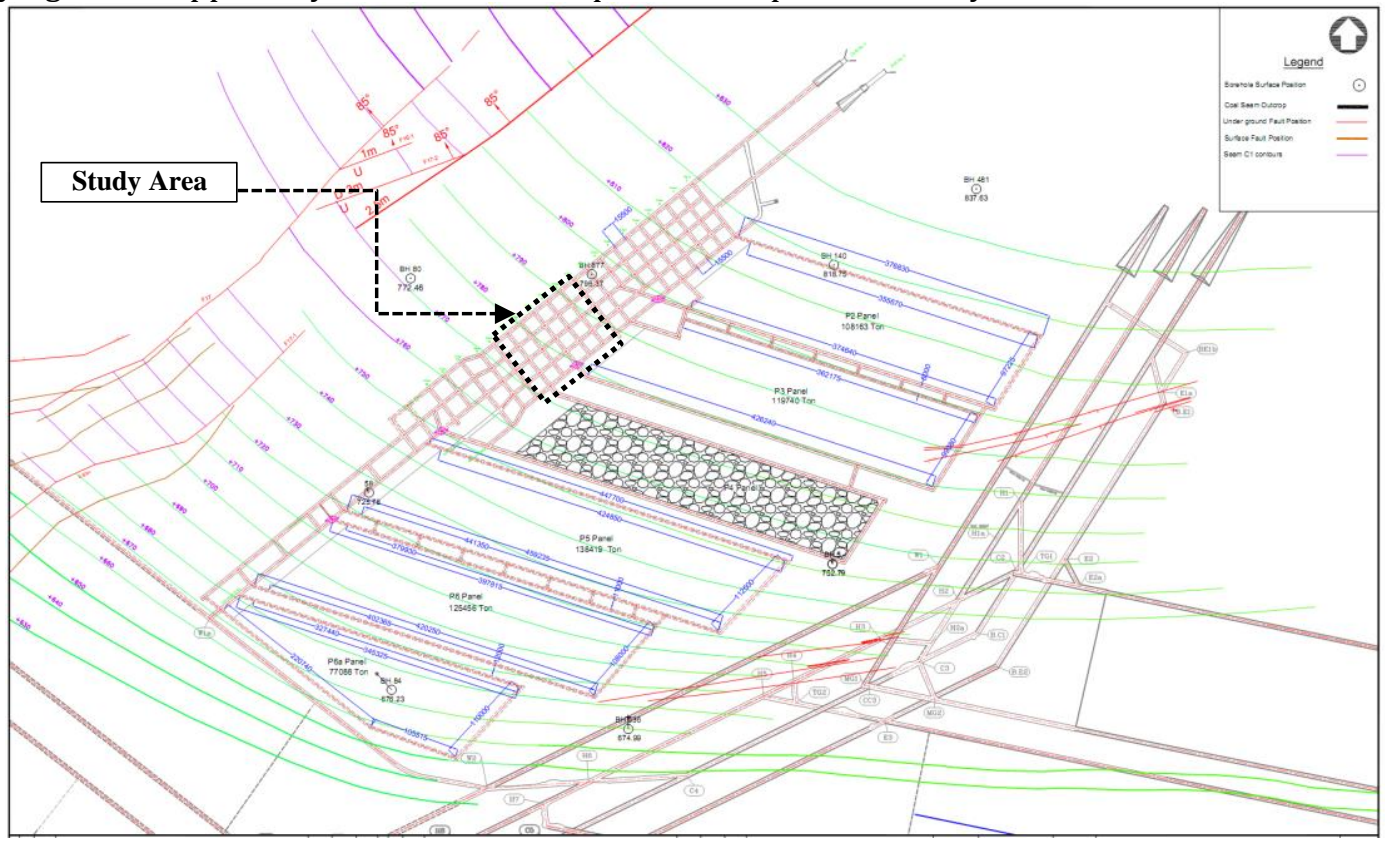

Figure 2. A view of the study area in TCM [10]

\subsection{Model Geometry}

According to room and pillar method and also tectonic procedures and layering in the study area, for drawing the geometric models in the FLAC3D the cubic meshing is used. Accordingly, with respect to the studied area as shown in Fig. 2 , the dimension of the block is considered $90 \times 110 \times 62$ meter along the $\mathrm{X}, \mathrm{Y}$ and $\mathrm{Z}$ directions respectively. The interval of mesh is considered 0.5 meters in coal seam and 1 meter in the other layers.

It should be noted that in order to reduce the volume of data processing, only 40 meters of overburden is modeled. Therefore, at the top of the model, a vertical force (1.35 MPa) is applied to simulate the overburden weight.

The ratio of horizontal stress $\left(\sigma_{h}\right)$ to the vertical stress $\left(\sigma_{v}\right)$ in various areas is different and heavily depends on the tectonics of the region. In this study due to a lack of measurement in-situ stress in the studied area, the theory value of horizontal stress is calculated using the following equation [5]: $\sigma_{h}=\frac{v}{v-1} \sigma_{v}+\frac{\beta E G}{1-v}(H+1000)$

where $\sigma_{v}$ and $\sigma_{h}$ are the vertical and horizontal stresses (MPa), E is Young's modulus of rock (2000 MPa), $v$ is Poisson's ratio $(0.25), \beta$ is coefficient of thermal expansion of rock $\left(3 \times 10^{-}\right.$ $\left.5 /{ }^{\circ} \mathrm{c}\right), \mathrm{G}$ is geothermal gradient for coal mines $\left(0.03^{\circ} \mathrm{C} / \mathrm{m}\right)$ and $\mathrm{H}$ is overburden thickness (100 $\mathrm{m})$. The value of average horizontal stress based on the above equation will be equal 3.4 MPa. As a result, the ratio of horizontal stress to vertical stress in this study is taken as 1.4.

In this study the Mohr Coulomb strain softening (MCSS) model is used to simulate the behavior of pillars. The MCSS model requires parameters that describe the rate of cohesion and friction drop as a function of plastic strain [12].

\subsection{Material Properties}

One of the most important parts in numerical modeling is to assign the properties of material to the model. The material properties for this study are summarized in Table 1. 
Table 1. Input parameters in numerical modeling [10]

\begin{tabular}{|c|c|c|c|c|c|c|c|}
\hline Parameter & Unit & Coal & sandstone & Siltstone & Mudstone & $\begin{array}{c}\text { Silty } \\
\text { sandstone }\end{array}$ & Overburden \\
\hline Density $(\gamma)$ & ton $/ \mathrm{m} 3$ & 1.6 & 2.7 & 2.72 & 2.6 & 2.72 & 2.65 \\
\hline Elastic Modulus (E) & GPa & 0.7 & 7.39 & 2.64 & 1.99 & 7.2 & 3.34 \\
\hline Cohesion (C) & $\mathrm{MPa}$ & 0.50 & 1.19 & 0.65 & 0.18 & 0.80 & 0.7 \\
\hline Tensile strength $\left(\sigma_{t}\right)$ & $\mathrm{MPa}$ & 0.10 & 0.4 & 0.20 & 0.01 & 0.25 & 0.3 \\
\hline Poisson's ratio $(\vartheta)$ & - & 0.27 & 0.3 & 0.28 & 0.3 & 0.3 & 0.29 \\
\hline Internal friction angle $(\varphi)$ & Degree & 20 & 51 & 40 & 24 & 30 & 36 \\
\hline Dilation angle $(\psi)$ & Degree & 5 & 15 & -- & -- & -- & -- \\
\hline
\end{tabular}

\subsection{Room and Pillar Extraction Sequence}

In this study to simulate the load on the pillars, the extraction of entries and crosscuts have been performed in stages and after each stage, the model is equilibrium. So first, the entries are created in $\mathrm{Y}$ direction and then by extraction of crosscuts in $\mathrm{X}$ direction the pillar is formed. A view of extracted rooms and remaining pillars in numerical model is shown in Fig. 3.

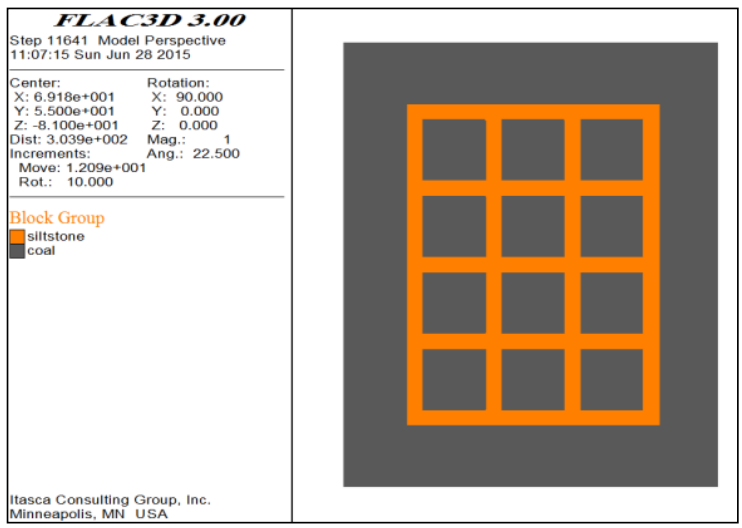

Figure 3. A view of study area in FLAC3D software

In order to evaluate the stress distribution and displacement during the recovery process of pillar, some points and scanline are arranged on the entries and pillar. The location of given points and scanlines are shown in Fig. 4.

\subsection{Modeling the Support System}

The support system was applied in the model similar to the designed support system in TCM. The support system in this mine is a combination of wire mesh and resin rockbolt for roof of entries. The installed support systems are shown in Fig. 5.

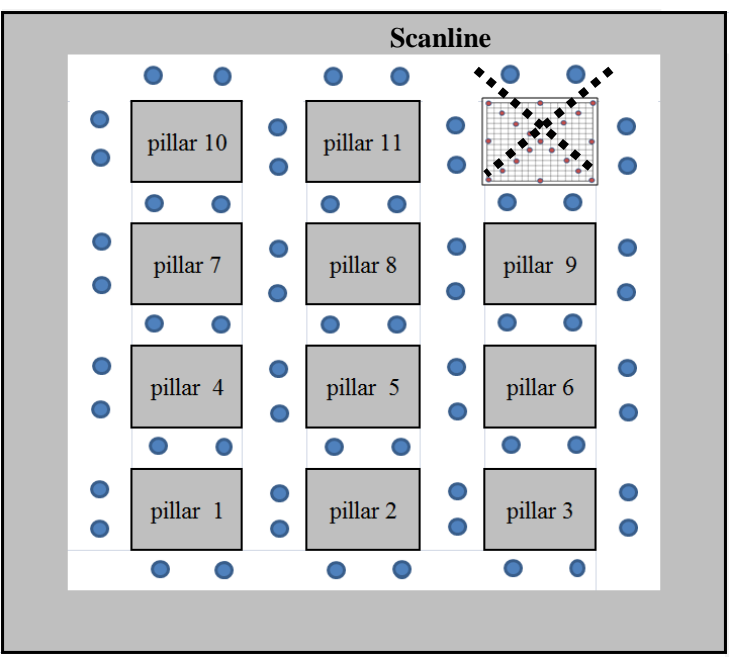

Figure 4. The location of given points on pillars and roof of entries

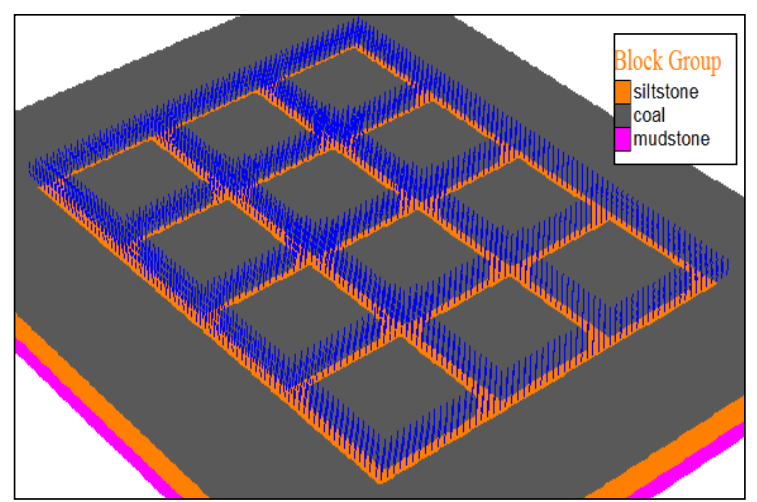

Figure 5: Overview of modeled support system

The mechanical properties of rockbolt and their arrangement is shown in Tables 2 and 3.

Table 2. Characteristics and arrangement of bolts in TCM $[3,15]$

\begin{tabular}{ccccc}
\hline Diameter & $\begin{array}{c}\text { Row } \\
\text { spacing }\end{array}$ & Length & $\begin{array}{c}\text { Number of } \\
\text { bolts in } \\
\text { rows }\end{array}$ \\
\hline \multirow{2}{*}{ Roof } & $22 \mathrm{~mm}$ & 1 & $\begin{array}{c}\text { In entries } \\
1.8 \mathrm{~m}\end{array}$ & 5 \\
\cline { 3 - 3 } & & & $\begin{array}{c}\text { In junctions } \\
2.4 \mathrm{~m}\end{array}$ \\
\hline
\end{tabular}


Table 3. The mechanical properties of bolts and grout $[3,15]$

\begin{tabular}{lcc}
\multicolumn{1}{c}{ Properties } & Unit & Value \\
\hline Cross-sectional area & $\mathrm{m} 2$ & 0.000384 \\
Young's modulus & $\mathrm{GPa}$ & 200 \\
Tensile yield strength & $\mathrm{MPa}$ & 1 \\
$\begin{array}{l}\text { Grout stiffness per unit } \\
\text { length }\end{array}$ & $\mathrm{MPa} / \mathrm{m}$ & 10 \\
$\begin{array}{l}\text { Grout cohesive strength } \\
\text { (force) per unit length }\end{array}$ & $\mathrm{MPa} / \mathrm{m}$ & 100 \\
Grout friction angle & Degrees & 60 \\
\hline
\end{tabular}

\subsection{Estimating the Safety Factor of the Remaining Rib in Coal Pillar Recovery}

In order to estimate the safety factor of the remaining rib after any cutting, the pillar strength and induced stress should be measured. The strength of pillar and rib (S) is estimated using the CMRI pillar strength formula as given [5].

$$
S=0.27 \sigma_{C} h^{-\cdot 0.36}+\left(\frac{H}{250}+1\right)\left(\frac{W_{e}}{h}-1\right) \quad M P a
$$

where, $\sigma_{C}$ is the uniaxial compressive strength of cube sample of coal (9.76 MPa), and $\mathrm{H}$ is depth of cover $(100 \mathrm{~m}), \mathrm{h}$ is extraction height $(2 \mathrm{~m}), \mathrm{W}_{\mathrm{e}}$ is effective width of rectangular pillar $\left(4 A / C_{p}\right)$, A is area of rib (pillar) and $C_{P}$ is rib (pillar) perimeter (m). By using Equation 2, the pillar strength with dimensions of $15 * 15$ meters (center to center) will be equal to $11.2 \mathrm{MPa}$. In this study the vertical stress on the pillar is estimated by numerical modeling for all phases of pillar recovery. Based on the recent experiences of the pillar recovery in the room and pillar method, some criteria are provided for stability of the pillars/rib of mining, which is given in Table 4 [5].

Table 4. Evaluation the stability of pillar and rib in the room and pillar method [5]

\begin{tabular}{ll}
\hline $\begin{array}{c}\text { Factor of safety of } \\
\text { pillars/ribs }\end{array}$ & \multicolumn{1}{c}{ Stability } \\
\hline & $\begin{array}{l}\text { Long term stability i.e. } \\
\text { Pillars/ribs are not going to fail at all; } \\
\text { In other words, they may be treated } \\
\text { as indestructible pillars. }\end{array}$ \\
\cline { 2 - 2 } Factor of safety $=1-2$ & $\begin{array}{l}\text { Short term stability i.e. it may fail } \\
\text { within few years. }\end{array}$ \\
\cline { 2 - 2 } $0.6 \geq$ Factor of safety & Stable for few days. \\
\hline
\end{tabular}

\subsection{Modeling and Analysis of Coal Pillar Recovery}

According to dimensions of pillar and entries of room and pillars in the extracting area in the TCM (Fig. 6), the percentage pillar recovery before pillar recovery is as follows:

$$
\begin{aligned}
& R=\frac{A_{m}}{A_{t}} \times 100 \rightarrow R=\frac{A_{t}-A_{p}}{A_{t}} \times 100 \rightarrow R= \\
& \frac{(19 * 19)-(15 * 15)}{(19 * 19)} \times 100 \cong 38 \%
\end{aligned}
$$

where, At: the tributary area of pillar, Am: extracted area, $A_{p}$ : the area of pillar and $R$ : extraction ratio.

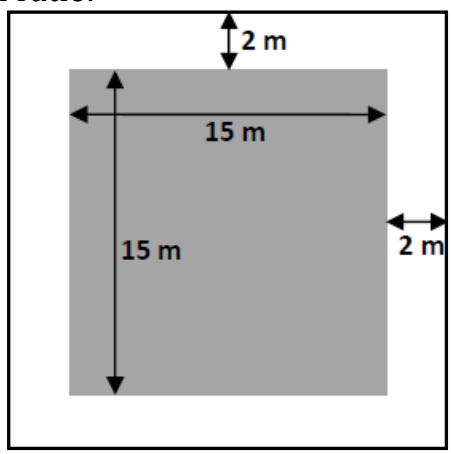

Figure 6. The tributary area for calculating the percentage of extraction recovery

In this study, The"Modified split and fender" and "Shortwall" methos are chosen from among the existing methods of pillar recovery for numerical modeling. The "Modified split and fender" method for simaltanious multiple face, with capability of high mechanization, mobile roof support (MRS/BLS) and recovery few pillars together, provides conditions to supply the sufficient number of production sites and prevent delays in production. The shortwall method is selected because Tabas central coal mine initially was designed for room and pillar mining method but currently, due to low recovery, it is extracted by traditional shortwall mining method.

\subsubsection{Coal Pillar Recovery with Modified Split and Fender Method}

The modified split and fender recovery method starts on three rows of pillars. In the first stage, the split is created in the first and second rows along the long axis of pillar. Then fenders are removed in the first row. After the extraction of end fenders in the first row, the extraction of fenders in second row starts and simultaneously the split along the long axis of third row is completed. The process will continue to extract all the pillars of the area [13]. Details are shown in Fig. 7.

In order to evaluate the recovery percentage of this method, in each stage of cutting, the value of stress variation and displacements is measured variation of the vertical stress on the remaining ribs at cut $1,10,20$ and 30 in the modified split and fender method is shown in Fig. 8. 


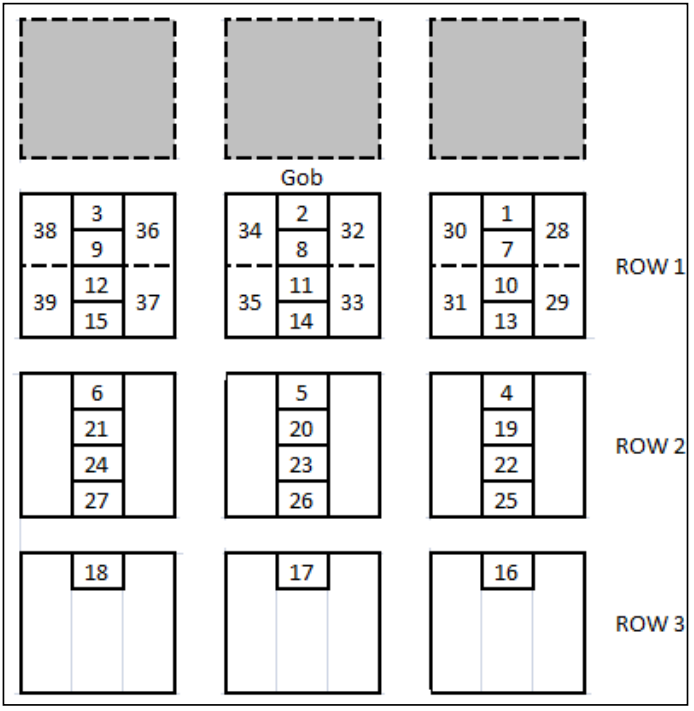

Figure 7. Modified split and fender cutting sequence, retreat mining method [13]

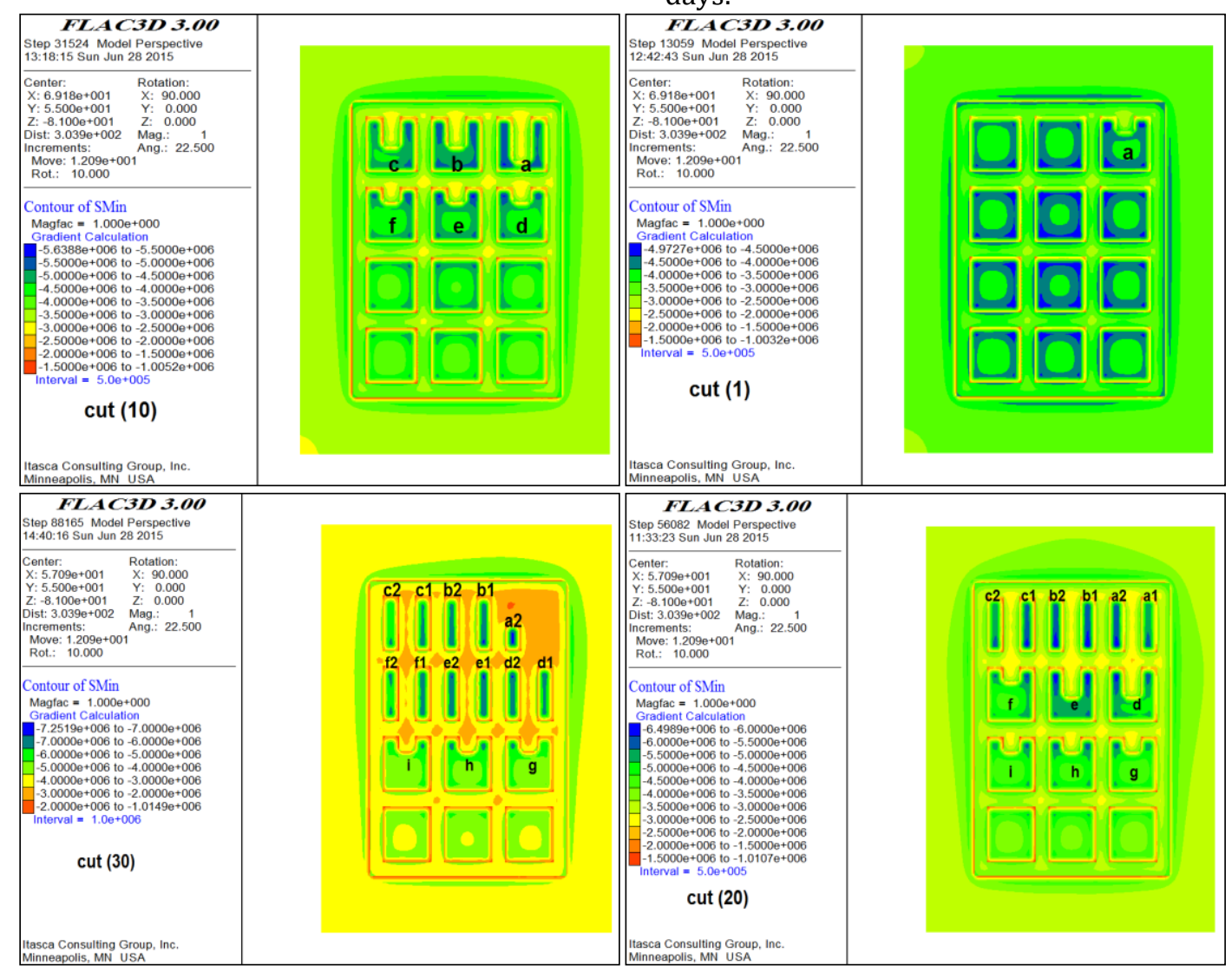

Figure 8. the vertical stress variation on the remaining ribs at cut 1, 10, 20 and 30 in the modified split and fender method
It is obvious that by increasing the number of cuttings in the recovery process and reducing the area of remaining ribs, the vertical stress on the remaining ribs will increase. The vertical stress before cutting is $4.8 \mathrm{MPa}$ and is increased to 7.2 $\mathrm{MPa}$ at cutting 30 (Fig. 9) In order to have a better analysis, the information from the induced vertical stress contours on the roof and the values of safety factor of ribs in sequential cutting (pillar strength is calculated using Equation 2) are shown in Fig. 10.

The descending trend of charts proves that by increasing the recovery process, the safety factor of rib is reduced. For example, in the rib (a) the highest recovery is done, the safety factor has been reduced to about 0.67 . The ribs ( $\mathrm{g}$, $\mathrm{h}$ and $\mathrm{i}$ ) are stable, because this ribs are in the early stages of recovery process. Therefore, according to Table 4 , it can be concluded that they have located in the failure zone and stable for a few days. 


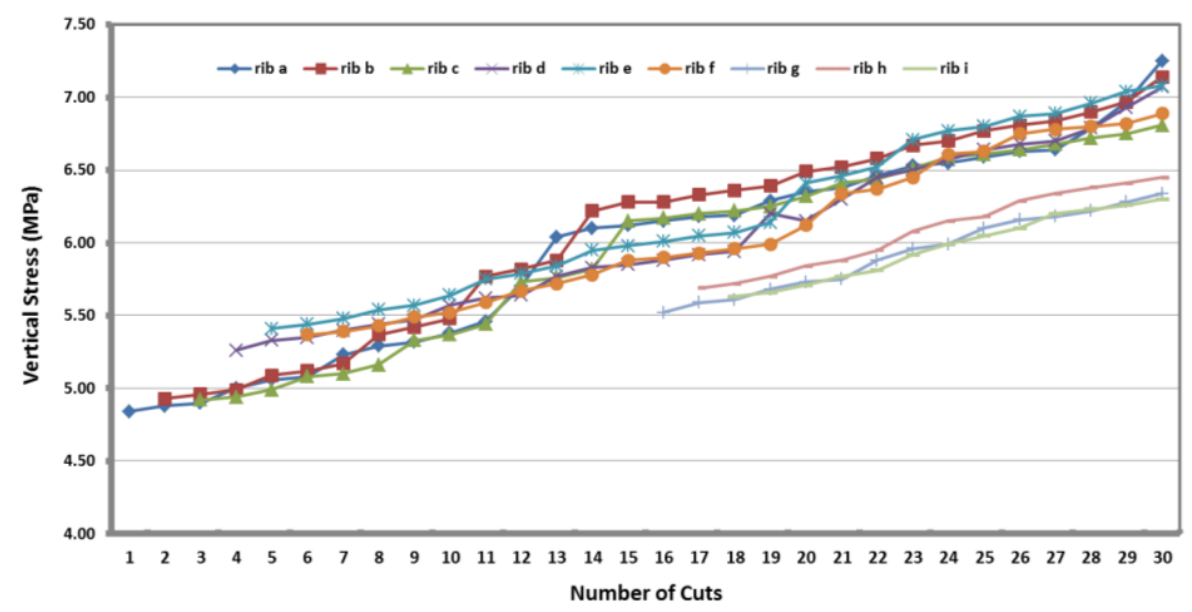

Figure 9. The vertical stress variation on the ribs by increasing pillar recovery

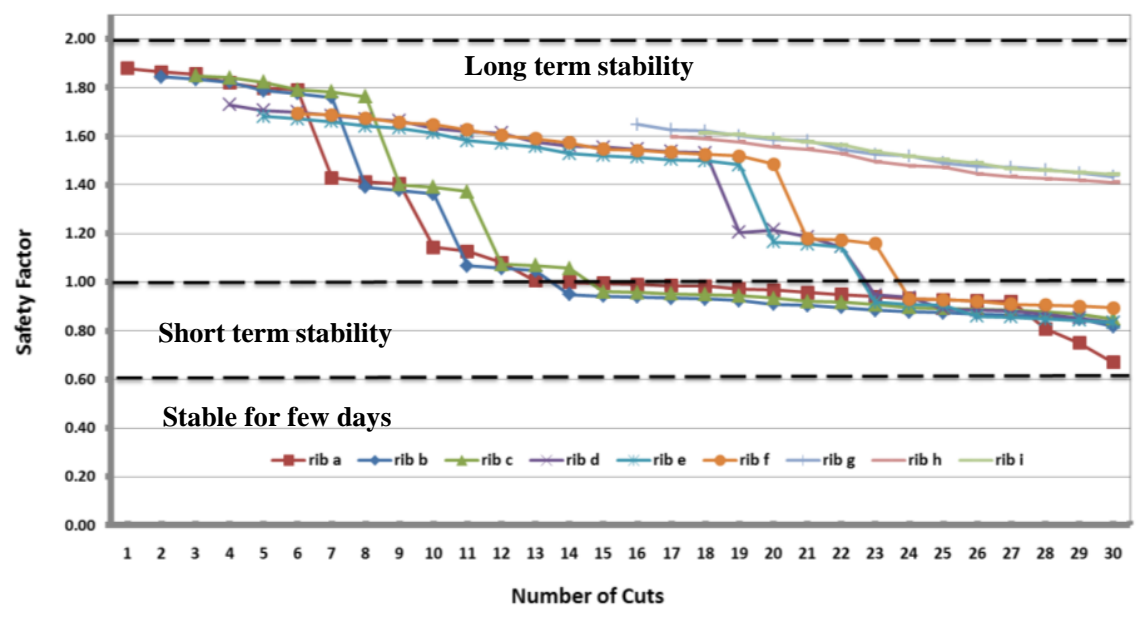

Figure 10. The safety factor variation of ribs in the stages of pillars recovery

The value of displacements in the roof is 18 $\mathrm{mm}$. it can be concluded that the ribs have failed but the failure has not occurred in the roof. It is expected that continued recovery process of the other pillars will destroy these ribs.

One of the main criteria in determining the maximum recovery and calculating the recovery percentages of pillar is evaluating the plastic zone of remaining ribs from the cutting progress. In order to assess the stability of pillar, the pattern of plastic zone should be analyzed. For example, the plastic zone of ribs as a result of cutting progress (cutting of 5, 15 and 30) is shown in Fig.
11. By increasing the pillar recovery, the plastic zone is increased. Finally, in section 30, in addition to the rib ( $\left.\mathrm{a}_{2}\right)$ which becomes full plastic state, the other ribs of the first row almost completely become full plastic. Finally, according to plastic zone and the values of the safety factor of ribs (Fig. 10), the cutting 30 is determined as the ultimate of recovery and from the Equation 3 the recovery percent is calculated $70 \%$ as follows:

$$
R=\frac{(57 * 19)-(4 * 15 * 3)}{(57 * 19)} \times 100 \cong 70 \%
$$




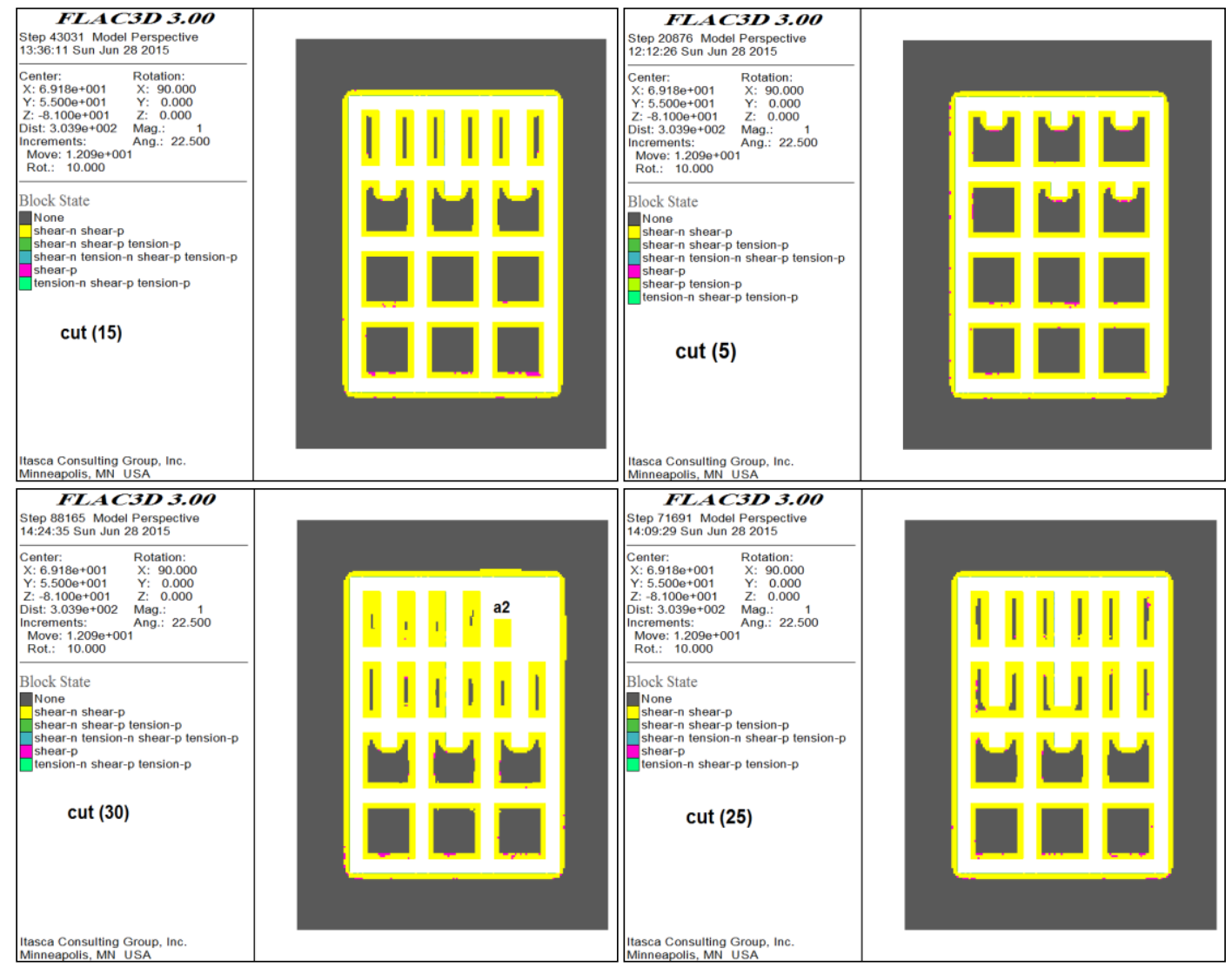

Figure 11. The plastic state of ribs by increasing pillar recovery

\subsubsection{Coal Pillar Recovery with Shortwall} Method

In shortwall method, by estimating the cavability of upper layer of coal seam and performing the other administrative and technical studies, the remaining pillars in a room will be recovered using the mechanization machinery in the shortwall method. Thus, according to the designed plan, the whole extracted area of room and pillar method is turned to the shortwall stope. Depending on the elements of length in the model, the panel can be extracted in the retreat method from the row 1 (Fig. 7). It should be noted that each pillar is extracted by 15 cuts.

In modeling process, after each cut and achieving equilibrium, the value of vertical stress variation, displacements and plastic zone are evaluated and analyzed. The vertical stress variation on the ribs at cut $1,5,9$ and 11 are shown in Fig. 12.

According to Fig. 12, it can be seen that by increasing the number of cut and reduction of the area of ribs; the vertical stress on the ribs is increased in the cutting 10 and reach to $6.8 \mathrm{MPa}$ in the cutting 11.

Because the strength of pillar reaches the yield strength at the cutting number of 11 , the vertical stress on the ribs is reduced. In other word, the bearing capacity of pillar is reduced. The vertical stress variation after each cut is shown in Fig. 13.

In order to have a better analysis, based on the vertical stress contours in the roof the values of safety factor of ribs in sequential cutting are calculated as shown in Fig. 14. Bold horizontal lines on the graph represent the stability criteria of ribs. 


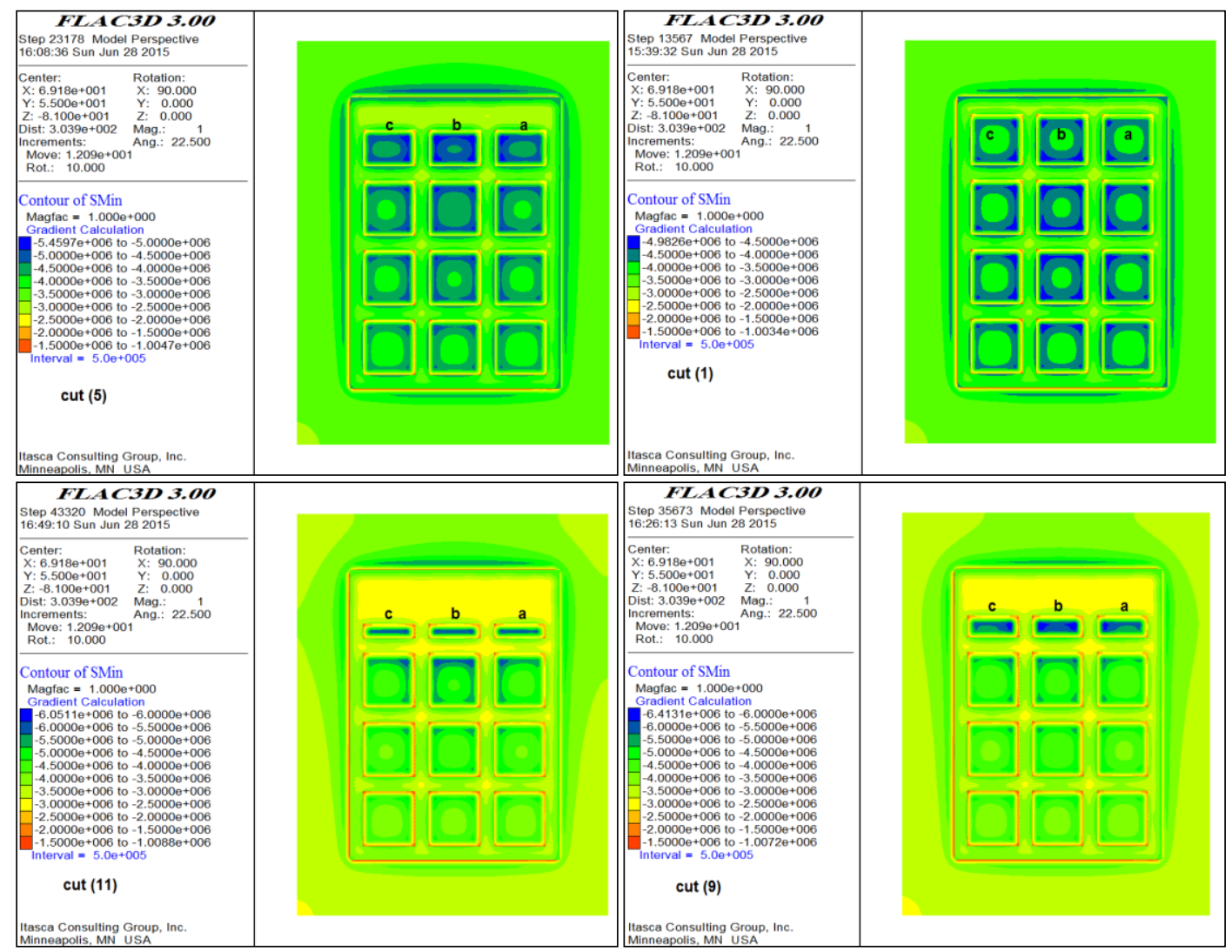

Figure 12. The vertical stresses variation on the ribs at cuttings 1, 5, 9 and 11

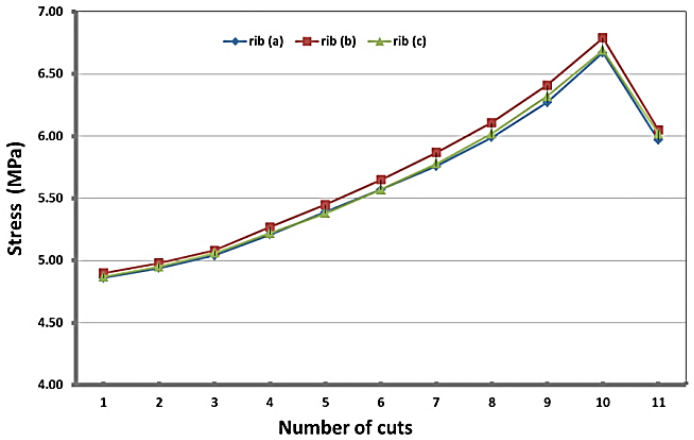

Figure 13. the vertical stress variation on the ribs in the stages of pillars recovery

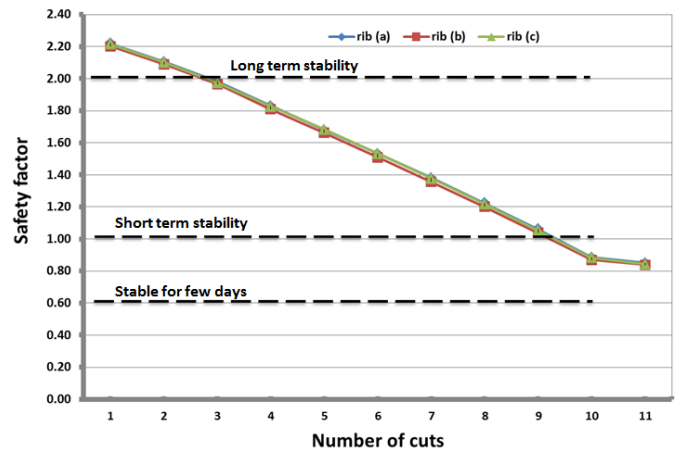

Figure 14. The safety factor variation of ribs in the stages of pillars recovery
Similar to modified split and fender method, the downward trend of chart proves that by increasing the recovery process, the safety factor of ribs is reduced. Since all the pillars of a row have been recovered simultaneously, for all three ribs (a, b and c) the increase of stress and reduction of the safety factor is almost similar. In the final stages of recovery, the ribs have safety factor less than 1 . Therefore, according to Table 4 it can be concluded that they are stable for a few days.

One of the main criteria for determining the maximum recovery and calculating the percentages of pillar recovery in this method is the plastic state in the remaining ribs during cutting progress. In Fig. 15, plastic zones in the ribs with increasing the pillar recovery are shown. As it can be seen in Fig. 15, by increasing the pillar recovery, the plastic zone is increased. In cutting 11 the remaining ribs ( $a, b$ and $c)$ are fully plasticized. Finally, according to plastic zone and the values of the safety factor of ribs, cutting number 11 is set as the ultimate recovery and from the Equation 3 the recovery percent is calculated $82 \%$ as follows:

$R=\frac{(57 * 19)-(4 * 15 * 3)}{(57 * 19)} \times 100 \cong 82 \%$ 


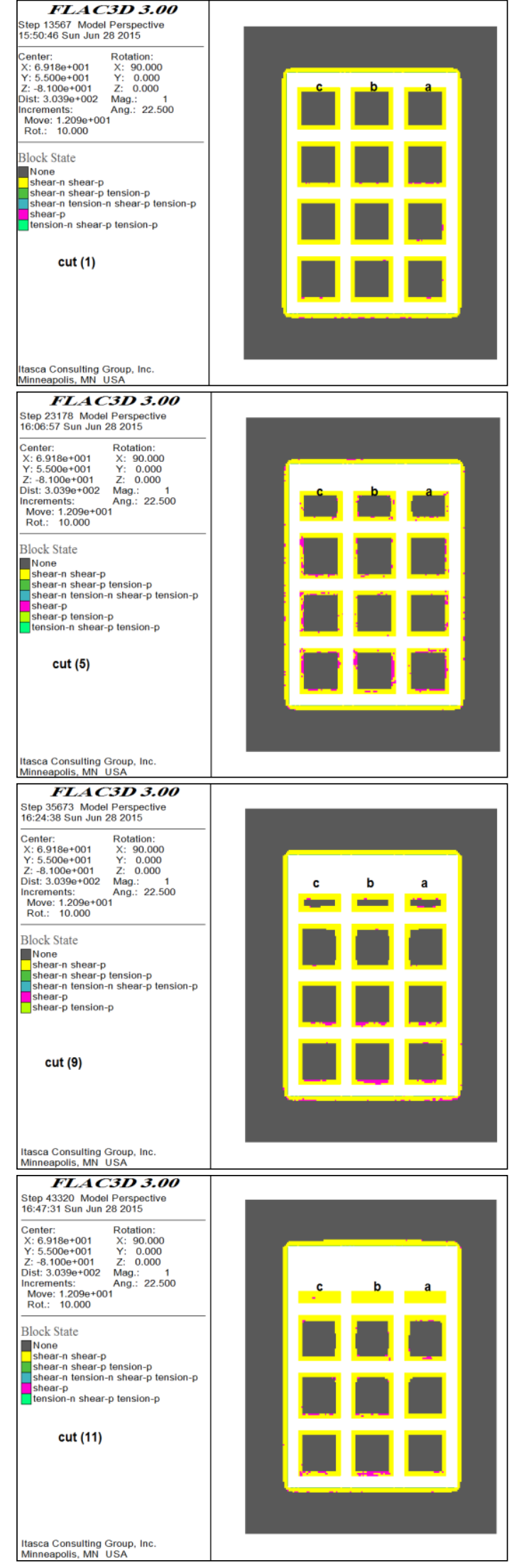

Figure 15. The plastic state of ribs by increasing pillar recovery in cut 1, 5, 9 and 11

\subsection{Validation of the Numerical Results}

In order to validate the numerical model, the amount of roof displacement obtained from numerical modeling is compared with data obtained from the instrument installed in the roof of entries in TCM. The instrument type in TCM is Telltale. This telltale estimates displacement in two moods ( $A$ and $B$ ). The monitoring points in the TCM that has been installed at the intersection of entries are shown in Fig. 16.

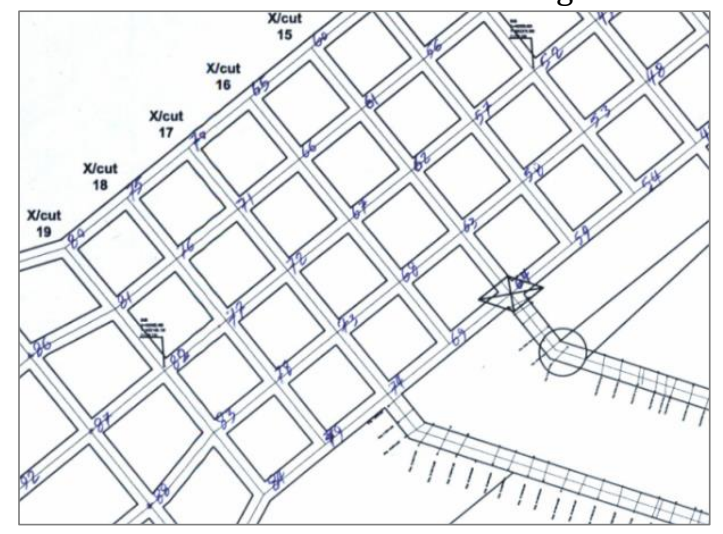

Figure 16. the monitoring point pattern in the TCM

As can be seen in Fig. 17, the rate and procedure of vertical displacement changes recorded in the monitoring point and results of the numerical modeling are matched with each other. As a result, it can be concluded that the model is made in good standing and the results of modeling with a good approximation are reliable.

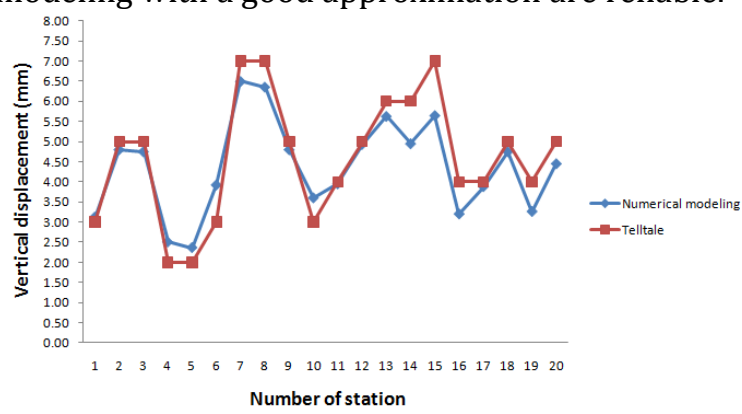

Figure 17. Comparison of vertical displacement from monitoring point in TCM and numerical modeling result before pillar recovery

\section{CONCLUSION}

In this study, "Modified split and fender" and "Shortwall" method were compared using the numerical modeling for pillar recovery in room and pillar coal mining in Tabas central coal mine. According to the numerical modeling, the most important results are as follows:

- Based on the safety factor of ribs and distribution of the plastic zone in the modified 
split and fender method, the cutting 30 and in shortwall method the cutting 11 was considered as the ultimate pillar recovery. The amount of recovery in the modified split and fender and shortwall methods from $38 \%$ (before recovering) increase respectively to 70 and 82 percent (after recovery).

- By increasing the pillar recovery process, it can be seen that, in the shortwall method until the cutting 9, all of ribs have a safety factor greater than 1, and in the cutting 11, the safety factor is reduced to about 0.8 . But in the modified split and fender method from the cutting 20 to the next, most of ribs have a safety factor less than 1 and in the cutting 30 the safety factor especially in the first row is reduced to 0.7. As a result, it can be concluded that the remaining ribs in the modified split and fender method are less stable, and their probability of failure and collapse during the process of completing the cuttings is more.

- The amount of vertical stress on the ribs in the modified split and fender method during the recovery process is ascending and is increased from 4.7 $\mathrm{MPa}$ to $7.25 \mathrm{MPa}$ in cutting 30 . So, by considering the fact that the amount of vertical stress in the shortwall starts from the $4.7 \mathrm{MPa}$ and with increasing the recovery process is increased to $6.7 \mathrm{MPa}$.

- In the method of modified split and fender the length of cutting is shorter than the shortwall method, which causes the operator to spend less time in high-risk area of working. According to the roof displacement, the maximum displacement in modified split and fender is about $19 \mathrm{~mm}$ and in shortwall is about $17 \mathrm{~mm}$.

Finally, in addition to the relative superiority of shortwall with recovery percent of $82 \%$ compared to the modified split and fender method with recovery percent of $70 \%$, this method is more favorable for pillar recovery in TCM.

\section{REFERENCES}

[1] Hustrulid, W. A., Bullock. R.L., (2001). Underground mining methods: Engineering fundamentals and international case studies. SME.

[2] Kauffman, P. W., Hawkins, S. A., and Thompson, R. R., 1981, Room and Pillar Retreat.

[3] Farmer I. 1992, Room and Pillar mining, in: SME Mining Engineering Handbook, Second edition, ed. By Hartman H. L., Society for Mining,
Metallurgy, and Exploration, Inc., SME/AIME, Co, Sec. 18.1, pp. 1681-1701.

[4] Mark, C., Chase, F., \& Pappas, D. (2003). Reducing the risk of ground falls during pillar recovery. Transactions-Society for Mining Metallurgy and Exploration Incorporated, 314, 153-160.

[5] Kushwaha, A., Banerjee, G., 2005, Exploration of developed coal mine pillars by shortwall mining-a case example, International Journal of Rock Mechanics \& Mining Sciences 42, pp 127-136.

[6] Qiyami, R., 2009, designed pillar recovery in the room and pillar extraction, Master's thesis, Tehran University, School of Mining Engineering (In Persian).

[7] Singh, A. K., Singh, R., Maiti, J., Kumar, R., \& Mandal, P. K. (2011). Assessment of mining induced stress development over coal pillars during depillaring. International Journal of Rock Mechanics and Mining Sciences, 48(5), 805-818.

[8] Ghasemi E, Shahriar K, 2012, a new coal pillars method in order to enhance safety of the retreat mining in room and pillar mine, safety science 48, 1304-1312.

[9] Najafi, M., Jalali, S.E., Yarahmadi, A.R., Sereshki, F., 2011, Prediction of the Confidence Interval for Stability Analysis of Chain Pillars in Coal Mines, Journal of Safety Science, Vol. 49, Issue 5, pp 651-657.

[10] Anon, 2005. Basic Design of Tabas Coal Mine Project, Report-Mining. Vol 1 of 5.

[11] ADAM Consulting engineering, 2005, Central Mine Design Report for NISCO, National Iranian Steel Co.

[12] Mortazavi, A., Hassani, F. P., \& Shabani, M. (2009). A numerical investigation of rock pillar failure mechanism in underground openings. Computers and Geotechnics, 36(5), 691-697.

[13] Campoli, Alan A., David C. Oyler, and Frank E. 1989, Chase. Performance of a novel bump control pillar extracting technique during room-and-pillar retreat coal mining. US Department of the Interior, Bureau of Mines.

[14] Liu, G., Li, L., Yang, X., and Guo, L. (2016). Numerical analysis of stress distribution in backfilled stopes considering interfaces between the backfill and rock walls. Int. J. Geomech.

[15] Najafi, M., Shishebori, A., \& Gholamnejad, J. (2016). Numerical estimation of suitable distance between two adjacent panels' working faces in shortwall mining. International Journal of Geomechanics, 17(4), 04016090. 